\title{
A IMPORTÂNCIA DA EDUCAÇÃO AMBIENTAL NA SOCIEDADE CONTEMPORÂNEA
}

Olivie Samuel Paião, Ana Augusta Westin Ebaid

Universidade do Oeste Paulista - UNOESTE, Curso de Direito, Presidente Prudente/SP. E-mail: oliviesamuel@hotmail.com

\section{RESUMO}

O presente artigo tem como objetivo apresentar uma reflexão sobre a importância da educação ambiental na sociedade contemporânea, propondo a adoção de uma nova postura ética, onde se espera que o comportamento humano entre em sintonia com os recursos da natureza. Neste sentido, será realizado um estudo sobre as práticas sociais que estão sendo propostas pelo Estado, no que tange às questões que se referem à educação ambiental. A metodologia constou de pesquisas bibliográficas. Os dados obtidos foram analisados utilizando-se do método hipotético dedutivo. Conclui-se que o meio ambiente, com toda a sua importância para cada ser existente no planeta, precisa de ferramentas que eduquem as pessoas, a fim de que preservem um meio ambiente adequado à boa qualidade de vida. Entretanto, por mais que exista regulamentação de comportamentos (lei), o resultado almejado não vem sendo efetivado.

Palavras-Chave: Educação, Ambiental, Sociedade, Contemporânea.

\section{EDUCATION OF ENVIRONMENTAL IMPORTANCE IN CONTEMPORARY SOCIETY}

\begin{abstract}
This article aims to present a reflection on the importance of environmental education in contemporary society, proposing the adoption of a new ethical stance where it is expected that human behavior between in tune with nature's resources. In this sense, there will be a study on social practices that are being proposed by the State regarding the issues that relate to environmental education. The methodology consisted of bibliographic research the data were analyzed using the hypothetical deductive method. It is concluded that the environment with all its importance for every existing thing on the planet, need tools in order to educate people, to preserve an environment adequate to good quality of life. However much there is regulation of behavior (law), the desired result has not been effective.
\end{abstract}

Keywords: Education, Environment, Society, Contemporary. 


\section{INTRODUÇÃO}

No ordenamento jurídico brasileiro, a Constituição Federal de 1988 incluiu a Educação Ambiental como regramento para que o meio ambiente fosse observado com maior ponderação, utilizado com responsabilidade e respeitado. Também foi incluído o acesso à Educação Ambiental para as instituições escolares, em todos os seus níveis.

A Educação Ambiental surgiu para tentar resgatar a dinâmica entre o ser humano e o meio ambiente, para mostrar a importância deste e voltar a atenção para o tema, que, atualmente, é o de maior relevância para a realidade declinante na qual o planeta está inserido. Por meio da educação ambiental, pode-se ter o embasamento necessário para as futuras ações e criações, levando em conta que as anteriores foram mal pensadas e criadas somente como paliativos e que não tiveram os efeitos necessários no que diz respeito à tentativa de recuperação da condição anterior do meio ou, ao menos, à redução dos danos causados à natureza.

O papel do educador ambiental é propor novos hábitos e novas posturas que garantam a boa qualidade de vida aos seres do planeta. Neste sentido, o escopo deste artigo é analisar, de forma específica, se as ações que estão sendo adotadas por parte do Estado estão sendo realmente efetivas, no que tange à proteção do meio ambiente.

\section{METODOLOGIA}

O artigo foi embasado em pesquisa bibliográfica, da qual resultou a leitura e análise de leis, resoluções e artigos eletrônicos. Os dados foram examinados com a aplicação do método hipotético-dedutivo, isto é, partindo do geral para o particular. Concomitantemente, as informações coletadas foram analisadas e confrontadas de forma dialética.

\section{DISCUSSÃO}

NOÇÃO DE MEIO AMBIENTE

O conceito jurídico de meio ambiente, para muitos doutrinadores, é ainda indeterminado, conforme observa Celso Fiorillo (2007, p. 21):

A expressão meio ambiente comporta uma infinidade de elementos ocasionando uma grande dificuldade na elaboração de seu conceito, a ponto de nem mesmo os especialistas conseguirem elaborar um em definitivo.

A mestra Isabella Guerra (2014, p.01 apud MILARÉ, 2001, p. 63) bem menciona em sua obra o quão complexo é o conceito de meio ambiente:

Numa concepção ampla, que vai além dos limites estreitos fixados pela Ecologia Tradicional, o meio ambiente abrange toda a natureza original (natural) e artificial, assim como os bens culturais correlatos. Temos aqui, então, um detalhamento do tema: de um lado como meio ambiente natural, ou físico, constituído pelo solo, pela água, pelo ar, pela energia, pela fauna e pela flora; e, do outro, com o meio ambiente artificial (ou humano), formado pelas edificações, equipamentos e alterações produzidos pelo homem, enfim, os assentamentos de natureza urbanística e demais construções. Em outras palavras, quer se dizer que nem todos os ecossistemas são naturais, havendo mesmo quem se refira a "ecossistemas naturais" e "ecossistemas sociais". Esta distinção está sendo, cada vez mais, pacificamente aceita, quer na teoria quer na prática.

Nesta perspectiva, a Lei 6.938/1981 elabora seu próprio conceito (BRASIL, 1981):

Art. 3 ㅇ - Para os fins previstos nesta Lei, entende-se por: 
I - meio ambiente, o conjunto de condições, leis, influências e interações de ordem física, química e biológica, que permite, abriga e rege a vida em todas as suas formas; [...]

Tal conceito, longe de satisfazer todas as aspirações doutrinárias, especialmente por ser um tanto simplista e não evidenciar a presença do meio ambiente artificial e cultural, foi importante por estabelecer um parâmetro inicial, que seria alargado, em 1988, com a nova Constituição Federal. Não que a Lei Maior traga uma nova definição em seu corpo legal, mas carrega em si uma série de princípios e garantias que explicitam ser o meio ambiente algo bem mais complexo do que a definição legal, apesar do forte caráter patrimonial contido no artigo 225.

Conforme se verifica, o meio ambiente é um conjunto de ecossistemas, é um conjunto de elementos vivos e não vivos, fatores naturais e não naturais, que integram o planeta Terra. Englobam-se, então, no meio ambiente, as classes químicas, físicas e biológicas. Há quem diga que tudo o que nos circunda deve ser considerado como parte do ambiente, posto que tudo, em cada fração terrestre, possui uma função da mais devida importância. O meio ambiente é referência à ecologia, e CASSINI (2005, p. 02) define ecologia como "a Ciência do Habitat. É a ciência que estuda as condições de existência dos seres vivos e as interações, de qualquer natureza, existentes entre esses seres vivos e seu meio".

O homem, desde sua concepção, é dependente dos recursos do meio ambiente. Na idade paleolítica, o meio de sobrevivência baseava-se na economia coletora, manifesta, principalmente, na caça, na pesca e na coleta natural. No período neolítico, houve a introdução de novos meios de caça, da domesticação de animais e da economia produtora. Logo, desde os primórdios, o meio ambiente tem sido necessário à sobrevivência e sustento dos seres humanos.

Com o passar dos anos, foi ocorrendo uma evolução tanto ambiental quanto humana, na qual algumas espécies surgiram e outras foram extintas. Neste processo, o ser humano foi avançando, cada vez mais, em seu conhecer, na construção e apropriação de saberes e ferramentas. O que, pela lógica, deveria trazer condições positivas, gerou situações de desequilíbrio, pois neste processo de evolução, houve um direcionamento insatisfatório, aconteceu o inverso do esperado, "o ser humano, totalmente desintegrado do todo, não percebe, mais, as relações de equilíbrio da natureza. Age de forma totalmente desarmônica, sobre o ambiente, causando grandes desequilíbrios ambientais..." (GUIMARÃES, 2005, p. 14).

Como o homem sempre foi dependente da natureza e acompanhou a extinção de muitas realidades deste mundo, esperava-se uma mentalidade que se comprometesse a preservar e a cuidar do meio em que está inserido. Mas, ao invés disto, foi em uma via totalmente antagônica, onde o interesse em ser superior e comandante de todas as outras coisas passou por cima da necessidade de se manter o equilíbrio ecológico. Com este sentimento, criou uma hierarquia na qual se colocou ocupando sempre a posição superior máxima, passou a observar as coisas do mundo não na relação de reciprocidade entre os elementos que o integram, mas, sim, olhando tudo de cima para baixo, colocando-se em posição de destaque.

Com essa postura antropocêntrica, o ser humano fez uma separação entre ele e a natureza. O consumo, para auferir lucro, é mais importante. Dessa forma, os recursos naturais começam a ser explorados e, na produção em massa de coisas que utilizam fatores do meio ambiente e na visão majoritária de consumo que adentra o setor mundial, a educação ambiental e as preocupações com o desequilíbrio do meio se perdem e ruinosas consequências acabaram emergindo.

Na década de 70, com a grande utilização dos recursos da natureza, surgiram os primeiros alertas de que começaram a findar os recursos que, até então, pareciam infinitos - mas, infelizmente, finitos (houve falta de conscientização, afinal, recursos finitos não atendem à necessidades infinitas). Então, com a onda de preocupação, movimentos em busca dessa 
conscientização começaram a ser abordados pelas pessoas e a tomar uma dimensão maior, quando o tema Educação Ambiental alavancou e tomou grandes proporções (MARCONDES, 2005, p.187/189).

A Educação Ambiental surgiu para tentar resgatar a dinâmica entre o ser humano e o meio ambiente, para mostrar a importância do mesmo e voltar a atenção para este tema, que, atualmente, tem significativa importância para a realidade em sua situação de declínio. Como já foi aqui observado, é por meio da educação ambiental que se pode ter o embasamento necessário para as futuras ações e criações, juntamente com os avanços anteriores, que foram mal pensados e criados somente como medidas paliativas, ficando a natureza, com isto desfalcada. (GUIMARÃES, 2005).

No ordenamento jurídico brasileiro, na Constituição Federal de 1988, a Educação Ambiental foi incluída como regramento para que o meio ambiente fosse visualizado com maior ponderação, utilizado com responsabilidade e respeitado. Também se incluiu, no mesmo capítulo, o acesso à Educação Ambiental para as instituições escolares, em todos os seus níveis.

As escolas servem como auxiliares de inclusão do ser humano na cidadania, que deve viver em uma sociedade cujos indivíduos precisam ser preparados para saber portar-se como sujeitos ativos e participantes, aprimorando suas opiniões e análises e formalizando suas críticas. Enfim, o trabalho realizado nas escolas deve vislumbrar o desenvolvimento de uma sociedade que tem clareza sobre os problemas que estão explícitos e implícitos no mundo e que busca soluções concretas para os mesmos. Esse ambiente de aprendizado desempenha, portanto, um importante papel de qualificação do indivíduo e, por isto, a Educação Ambiental foi acrescida aos componentes do ensino escolar.

De acordo com o Art 2ㅇ da Lei 9.795/1999 (BRASIL, 1999), “A Educação Ambiental é um componente essencial e permanente da educação nacional, devendo estar presente de forma articulada em todos os níveis e modalidades do processo educativo, em caráter formal e não formal".

"Com essa diretriz, os sistemas de ensino têm obrigação legal de promover, oficialmente, a prática de Educação Ambiental" (MEC, 2001, p. 15). De acordo com os preceitos normativos em vigor, Fiorillo (2015, p. 136) diz em sua obra que a Educação Ambiental deve incluída ao ensino escolar, nas seguintes palavras:

A educação ambiental deverá ser implementada no ensino formal, sendo desenvolvida no âmbito dos currículos das instituições de ensino públicas e privadas, englobando a educação básica, a superior, a especial, a profissional, e a de jovens e adultos.

No entanto, observa-se que tudo o que é preconizado e enfatizado pelo Ordenamento Jurídico está longe de alcançar o seu efetivo cumprimento na dimensão pretendida pela sociedade. No âmbito da educação infantil, a taxa de crianças que não conhecem ou não compreendem o significado do conceito de Educação Ambiental é alta e espantosa para os dias atuais, visto que a devastação se faz visível aos olhos de todos, logo se visualiza que não há o ensino da Educação Ambiental "preceitua-se a sua não implementação como disciplina específica no currículo de ensino (...) facultando-se apenas nos cursos de pós-graduação, extensão e nas áreas voltadas ao aspecto metodológico" (FIORILLO, 2015, p. 136). Sendo assim, de nada adianta essas crianças já terem ouvido falar ou conhecerem apenas as palavras que, formalmente, definem esse conceito se não realizam práticas responsáveis e condizentes com o modelo de Educação Ambiental almejado para a proteção do meio ambiente.

Para visualizar, nos dias atuais, um exemplo de degradação ambiental, não é preciso ir muito longe. A sociedade viu e vê imagens de empresas que poluem o meio ambiente, em massa, com a emissão espantosa de gases, como os aproximados $130 \mathrm{KM}$ do rio Tietê, que ficam no 
estado de São Paulo, e, ainda mais perto e presente no cotidiano da grande maioria, a emissão de poluentes (monóxido de carbono) ocasionados por veículos automotores. O papel de bala, quando descartado na natureza, pode até parecer inofensivo, mas é mais um auxiliar no entupimento de bueiros e nas dificuldades dos escoamentos de água, consequentemente corroborando com as enchentes, poluição de lagos, rios e mares. Muitos animais marinhos morrem ao ingerir tipos de plásticos, confundindo-os com alimentos.

Com a maior produção de bens, produtos e/ou serviços, a proporção de produção de lixo cresce na mesma proporção.

O meio ambiente limpo e saudável é um direito de todos, segundo o artigo 225 da Constituição Federal: "Todos têm direito ao meio ambiente ecologicamente equilibrado, bem de uso comum do povo e essencial à sadia qualidade de vida, impondo-se ao Poder Público e à coletividade o dever de defendê-lo e preservá-lo para as presentes e futuras gerações". Também o artigo 170 disciplina (BRASIL, 1988):

A ordem econômica, fundada na valorização do trabalho humano e na livre iniciativa, tem por fim assegurar a todos existência digna, conforme os ditames da justiça social, observados os seguintes princípios:

(...) VI- defesa do meio ambiente, inclusive mediante tratamento diferenciado, conforme o impacto ambiental dos produtos e serviços e de seus processos de elaboração e prestação.

A lei $n^{\circ} 9.605$ de 1998, discorre sobre os tipos de crimes ambientais, a fim de eliminar o uso abusivo e excessivo do meio ambiente. As classificações feitas são seis, a saber: crime contra a fauna; crime contra a flora; poluição e outros crimes ambientais; crimes contra o ordenamento urbano e o patrimônio ambiental; crimes contra a administração florestal e; infrações administrativas. (MILARÉ, 2001, p. 439)

As redações que falam sobre meio ambiente, seja nacional ou internacional, possuem caráter holístico, ou seja, visualizam o meio ambiente como um todo, como algo de competência e responsabilidade global, e não apenas de uma localidade. A visão é para o presente e, consequentemente, para o dia de amanhã. De tal forma que, se há uso sustentável hoje, haverá recursos para amanhã e depois de amanhã, assim, sucessivamente.

A Agenda 21 é um conjunto de diretrizes, conjunto de textos, que abordam problemas iminentes e é representada por países que se reuniram na ECO 92 (SCARLATO; PONTIN, 2011). Essa Agenda, segundo Milaré (2001, p. 48):

(...) de um lado, preconiza mudanças, de outro ela se apresenta com um caráter aglutinador, um marco referencial, seja na abordagem dos problemas, seja no equacionamento dos mesmos.

Quando o ser humano age, de maneira irresponsável, sobre o tutelado meio ambiente, este responde pelos danos causados, seja na esfera civil ou na penal. Logo, o Direito ambiental possui três funções de grande importância: a de prevenir, a de reparar e a de repressão.

Na esfera civil, o agente que lesiona o meio ambiente, por meio do dano ambiental público, deverá pagar uma indenização ao Estado, de tal forma que isto se direcione para uma restauração do ambiente, a fim de recompô-lo. Há duas "penalidades" mediante as quais a esfera civil direcionará o agressor, sendo a primeira mesmo que mais dificultosa, a recuperação do Estado anterior do ambiente, na qual o indivíduo deverá cessar todas as atividades que tenham periculosidade para o referido meio e começar a praticar atos que colaborem para a reconstrução daquilo que lesou. Caso a reparação ou recuperação não seja possível, a segunda opção é a indenização, em forma de dinheiro; e esta também exigirá que o sujeito, seja pessoa física ou a 
figura da pessoa jurídica, pare com as atividades danosas (MILARÉ, 2001, p. 420/423).

O problema da reparação indenizatória apresentada pelo dano civil é que não existe a possibilidade de se recompor todas as coisas. Um exemplo disso é quando se trata de um recurso finito que foi utilizado até a sua extinção. Não importará o valor a ser pago, pois, independente de valores, o recurso que foi extinto não retornará ao meio do qual foi retirado.

$\mathrm{Na}$ seara penal, a responsabilidade também independe de o sujeito ser pessoa física ou jurídica. Antes, era questionado se a pessoa jurídica poderia responder pelo ilícito, pois, no próprio código penal, o tipo penal discorre sobre condições do agente, fazendo relação a sua capacidade de entender $o$ ato. Logo se compreendeu que o sujeito praticamente agiu, geralmente, em nome de pessoa jurídica, o que ocasionou o rompimento de certo receio em atribuir-se a responsabilidade a uma pessoa jurídica (MILARÉ, 2001, p. 449).

As penas aplicadas variam entre privativas de liberdade, restritiva de direitos e multa. Apesar de a privativa de liberdade ser de ultima ratio, quando for esta, a sanção será de prisão simples para contravenções e dos outros modos para os crimes.

\section{CONCLUSÃO}

Conforme se verifica, o fiel objetivo da Constituição Federal ao incluir a Educação Ambiental como objeto de estudo social, não está sendo exitoso. Quando se refere ao ensino efetivo sobre ambiente, classificam-se os ensinos primários apenas como a propedêutica da questão. A aprendizagem sobre ambiente deve ser constante e nunca se estagnar, pois tudo muda, tudo se cria, tudo se transforma e o conhecimento precisa acompanhar esse processo de evolução. Se a base educacional não for fecunda e o povo (referindo-se, aqui, à sociedade como um todo) não se conscientizar da importância do meio ambiente e dos caminhos para os quais as ações humanas estão nos levando, as legislações e medidas jurídicas não serão suficientes para atender à proteção pretendida. É preciso formar uma postura ética, na qual os valores culturais do ser humano venham sobrepor-se às ações antrópicas e, com isso, alterar o seu modo de viver através das bases educacionais e das diretrizes ideológicas da preservação ambiental, para assim conseguir atingir o meio ambiente ecologicamente equilibrado e essencial à sadia qualidade de vida.

\section{REFERÊNCIAS}

BARBIERI, J. C. Desenvolvimento e Meio Ambiente - As estratégias de mudanças da Agenda 21- 13a ed. Editora Vozes, 2011.

BRASIL. Constituição (1988). Constituição da República Federativa do Brasil. Brasília, DF, Senado, 1998.

CASSINI, Sérvio Tulio. Ecologia: Conceitos Fundamentais. Disponível em: http://www.inf.ufes.br/ neyval/Gestao ambiental/Tecnologias Ambientais2005/Ecologia/CONC B ASICOS ECOLOGIA V1.pdf. Acesso em 17 set. 2016.

FIORILLO, C. A. P. Curso de direito ambiental brasileiro. 16a. ed. São Paulo: Saraiva, 2015.

FREIRE, P. Educação e Mudança. Rio de Janeiro: Paz e Terra, 1979.

FREIRE, P. Conscientização: teoria e prática da libertação - uma introdução ao pensamento de Paulo Freire. São Paulo: Cortez, 1980.

GUERRA, Isabella Franco. O Direito Ambiental. Disponível em: www.mackenzie.br/fileadmin/FMJRJ/coordenadoria pesq/.../direito ambiental.doc. Acesso em 17 
set. 2016

GUIMARÃES, Mauro. A dimensão ambiental da educação. 7.ed. Campinas,SP: Papirus, 2005. (Coleção Magistério: Formação e Trabalho Pedagógico)

GUIMARÃES, M. A Dimensão Ambiental na Educação. Papirus Editora, 1995.

MARCONDES, Sandra Amaral. Brasil, amor à primeira vista. São Paulo: Peirópolis, 2005.

MEC; SEF; DPE; COEA. Meio Ambiente na Escola- Parâmetros em Ação, 2001.

MILARÉ, E. Direito do Ambiente: doutrina, prática, jurisprudência, glossário. São Paulo: Editora Revista dos Tribunais, 2001.

MILARÉ, E. Legislação Ambiental do Brasil. São Paulo: Editora APMP, 1991.

ODUM, E. P. Fundamentos de Ecologia. 6ạ ed. São Paulo: Fundação Calouste Gulbenkian, 2004.

SCARLATO, F. C; PONTIN, J. A. Do Nicho ao Lixo- ambiente, sociedade e educação-18áEd. Atual Editora, 2009. 